\title{
Ultraviolet sunscreens in reef fish mucus
}

\author{
Maxi J. Eckes ${ }^{1, *}$, Ulrike E. Siebeck ${ }^{2}$, Sophie Dove ${ }^{3}$, Alexandra S. Grutter ${ }^{1}$ \\ ${ }^{1}$ School of Integrative Biology, University of Queensland, St. Lucia, Queensland 4072, Australia \\ ${ }^{2}$ Sensory Neurobiology Group, School of Biomedical Sciences, University of Queensland, St. Lucia, Queensland 4072, Australia \\ ${ }^{3}$ Centre for Marine Studies, ARC Centre of Excellence for Coral Reef Studies, University of Queensland, St. Lucia, \\ Queensland 4072, Australia
}

\begin{abstract}
Coral reef fishes were recently discovered to have ultraviolet (UV) radiation screening compounds, most commonly known as mycosporine-like amino acids (MAAs), in their external body mucus. However, little is known about the identity and quantity of MAAs in the mucus of reef fishes or what factors affect their abundance and distribution. Using spectrophotometry, we examined the relative field UV absorbance of fresh mucus and quantified the UV absorbance per mg of mucus using laboratory UV absorbance for 7 species of reef fishes (Labroides dimidiatus and Thalassoma lunare [Labridae]; Chlorurus sordidus, Scarus flavipectoralis, S. niger, S. rivulatus, and S. schlegelii [Scaridae]) from Queensland, Australia. For the first time in fish mucus, we identified and quantified MAAs using High Performance Liquid Chromatography. In addition, to examine geographical variation in MAAs, MAA absorbance in T. lunare mucus was compared among 3 different locations (Lizard Island, Heron Island, and North Stradbroke Island) on the coast of Queensland. The mucus of all fish investigated contained MAAs. Depending on the species, different combinations and quantities of the MAAs asterina-330, palythene and mycosporine-N-methylamine serine were present. UV absorbance and MAA levels in mucus of $T$. lunare from North Stradbroke Island were lower (mycosporine-N-methylamine serine) or absent (palythene) compared with mucus from Lizard Island and Heron Island. This study shows that the identity and quantity of MAAs in fish mucus not only varies among species but also within a species sampled in different locations. This suggests that the ecological role of MAAs in fishes is varied and complex and that several factors may affect the type and quantity of MAAs found in the mucus of reef fishes.
\end{abstract}

KEY WORDS: Mycosporine-like amino acids · MAA · Fish mucus · Geographical comparison · UV absorbance $\cdot$ UV protection

Resale or republication not permitted without written consent of the publisher

\section{INTRODUCTION}

Solar ultraviolet (UV) radiation can directly or indirectly damage tissues in both terrestrial and marine organisms (Berghahn et al. 1993) and is a common cause of cancer in terrestrial animals (Mason et al. 1998). Coral reefs typically have clear oligotrophic waters with a high UV transmission (Fleischmann 1989), yet are highly productive ecosystems that support a dense population of organisms (Reakla-Kudla 1997). The abundance of life in such marine surface waters is evidence of effective UV protection, potentially achieved by sunscreens (mycosporine-like amino acids, MAAs) (Dunlap et al. 2000), avoidance strategies (Karentz 2001), internal damage control (free radical quenching agents such as carotenoids, melanin, and scytonemin) (Karsten \& GarciaPichel 1996), or repair mechanisms (e.g. photolyase DNA repair) (Carell \& Epple 1998). Understanding how organisms protect themselves from UV is particularly urgent today, as depletion of stratospheric ozone from anthropogenic inputs of fluorocarbons has resulted in an increase in the amount of UV reaching the sea surface in some areas (Madronich et al. 1998). Furthermore, climate change is influencing the amount of UV reaching the earth's surface through changes induced mainly by cloud cover (WMO \& UNEP 2006). The southern Great Barrier Reef (GBR, Australia) has, for instance, experienced a significant increase in the number of cloud-free days over the last 10 yr (Masiri et al. in press). 
MAAs, also known as 'nature's sunscreens', are watersoluble nitrogenous compounds that perform a photoprotective function against solar radiation (Dunlap et al. 2000). MAAs of marine origin have broad absorption spectra, which typically peak between 309 and $360 \mathrm{~nm}$ (Tartarotti et al. 2004) and therefore absorb both UVB radiation ( 280 to $320 \mathrm{~nm}$ ) and UVA (320 to $400 \mathrm{~nm}$ ) (Dunlap \& Shick 1998). Examples of MAAs found in marine organisms include asterina-330, mycosporine-glycine, mycosporine-taurine, mycosporine-2-glycine, and mycosporine-N-methylamine serine palythene, palythine, palythinol, and shinorine (Dunlap \& Shick 1998).

Solar UV radiation reaching the earth's surface decreases with distance from the equator and with depth of water (Jerlov 1968). The latter decrease, however, mainly depends on the optical quality of water, which varies greatly between coastal and oceanic waters (Jerlov 1968). In clear oligotrophic tropical oceans, where most coral reef ecosystems are found, UV can penetrate deep into the water column (Hakkinen et al. 2002) and can affect major biological interactions to a depth of over $20 \mathrm{~m}$ (Dunlap et al. 1989). In the shallow waters of the GBR, animals may be exposed to 30 times the minimum UV dosage capable of causing sunburn in humans (Dunlap \& Shick 1998). Short wavelength UV has the potential to cause a wide range of other problems, such as physiological injuries due to direct damage or alterations to the structure of proteins, DNA, lipids and other biologically significant molecules (Sharma et al. 2005). This may lead to chronic depression of key physiological processes such as growth and reproduction (Mason et al. 1998).

MAAs have been identified in taxonomically diverse organisms, such as cyanobacteria, algae including microalgal-invertebrate symbionts, sponges, echinoderms, molluscs, cnidarians, arthropods, and fish (Dunlap et al. 2000, Shick \& Dunlap 2002). In fish, MAAs have been found in eggs, ocular tissue, and reproductive tissues (Dunlap \& Shick 1998).

Metazoans are unable to synthesise MAAs (Dunlap \& Shick 1998); only cyanobacteria, fungi, algae, and higher plants possess the requisite biochemical pathways to do so (Shick \& Dunlap 2002). Therefore, metazoans, such as fish, must obtain MAAs through their diet (Mason et al. 1998). However, almost nothing is known of the source of MAAs in fish or how they are processed, whether they can be stored, and how they reach their final destinations.

Recently, 'sunscreening compounds' were found in the external mucus of fish (Zamzow \& Losey 2002). Their presence in fish mucus appears to be a general characteristic of many reef fishes, with $90 \%$ of the coral reef fish species surveyed from Hawaii, the GBR, and Johnston Atoll showing UV absorbance in their mucus (Zamzow \& Losey 2002). Additionally, Zamzow
(2004) found that the UV absorbance of the mucus of the Hawaiian fish Thalassoma duperrey increased when experimentally exposed to UV. However, this occurred only if fish were fed a MAA-rich diet, suggesting that the fish can regulate MAAs according to UV exposure (Zamzow 2004). Finally, geographical differences in mucus UV absorbance have been found for tidepool fishes sampled across 30 degrees latitude on the coast of California, USA (Zamzow 2003). Whilst it is highly likely that these UV screening compounds are MAAs, to date this is only supported by reference to an unpublished biochemical analysis (J. P. Zamzow unpubl. data, in Zamzow 2004) of a single sample taken from a single fish species, T. duperrey (Labridae) (Zamzow 2004). More comprehensive information is needed to determine whether the presence of MAAs in fish mucus is a general phenomenon, given that the ability to absorb UV is not a property that is unique to MAAs (Zamzow 2004). Therefore, a biochemical analysis (minimally co-elution with known MAAs) is needed to provide conclusive evidence that these sunscreening compounds are indeed MAAs. Knowing the identity of MAAs in mucus can then be used to examine their source in fish and whether fish can vary MAA levels or alter their composition.

Using fish from Queensland, Australia, we determined, for the first time using reverse phase chromatography, the identity and relative quantity of MAAs in fish mucus. The specific questions addressed in this study were as follows: (1) Does UV absorbance in the mucus vary among reef fish species? (2) Are there inter- and intra-specific differences in the concentration and identity of MAAs in fish mucus? (3) Does MAA content in fish mucus within a species vary geographically? We selected several species of parrotfishes (Scaridae) because they have abundant mucus (M. Eckes pers. obs.), the cleaner fish Labroides dimidiatus (Labridae) because fish mucus is part of its diet (Grutter 1997), and the labrid Thalassoma lunare because it is found across a wide range of latitudes.

\section{MATERIALS AND METHODS}

Fish collection. Fish were collected in Queensland, Australia, from the reefs around Lizard Island $\left(14^{\circ} 41^{\prime} \mathrm{S}, 145^{\circ} 27^{\prime} \mathrm{E}\right)$ on 2 field trips in April and July 2005, from Heron Island (North Wistari reef; $23^{\circ} 51^{\prime} \mathrm{S}$, $152^{\circ} 01^{\prime}$ E) in August 2005, and from North Stradbroke Island $\left(27^{\circ} 49^{\prime} \mathrm{S}, 153^{\circ} 40^{\prime} \mathrm{E}\right)$ in September 2005. Fish were collected with a range of barrier nets and handnets from a depth of 5 to $10 \mathrm{~m}$. Live fish were transferred to holding tanks (maximum $100 \times 50 \times 50 \mathrm{~cm}$ ) supplied with running seawater for a maximum of $5 \mathrm{~h}$ prior to sampling their mucus. 
The UV absorbance and MAA identity of the mucus was measured using 3 types of analysis: absorbance of raw mucus measured in the field ('field UV absorbance'), absorbance of quantified extracted mucus ('laboratory UV absorbance'), and absorbance and identity of MAAs ('HPLC absorbance').

Mucus sampling and spectrometry for field UV absorbance. All mucus samples were measured fresh, before being frozen in liquid nitrogen for further analysis in the laboratory. Field measurements of UV absorbance were made using a method similar to that described by Zamzow (2004). External body surface mucus was sampled from each fish on the day of capture, and UV absorbance of the mucus was determined using a fibre optic spectrometer (USB2000, Ocean Optics). Using a dull blade, mucus was gently scraped off the entire dorsal flank of fish as described by Zamzow (2004). To measure field UV absorbance, mucus was placed on a UV-transparent microscope slide. The thickness of each mucus sample was standardized by using cover slips ( $0.25 \mathrm{~mm}$ thick) glued to both ends of the slide which acted as spacers. We used a laptop computer (DELL Inspiron 8200) from which the spectrometer could be controlled, a UV light source (PX-2, Ocean Optics), and a modified compound microscope that was used as a stage. A fibre optic cable (Ocean Optics, diameter $1000 \mathrm{~nm}$ ) connected to the UV light source was inserted into a metal holder. This was fitted into the microscope slot normally containing a lens and was used to illuminate the sample from above. The distance between the end of the cable and the sample could be adjusted with the focusing dial of the microscope. The sample was placed on the microscope stage and could be moved with $x-y$ micromanipulators. Light transmitted through the sample was collected by a $50 \mathrm{~nm}$ fibre-optic cable (Ocean Optics), fixed in the position where the condenser would normally be and analysed with the spectrometer. For each individual mucus sample, collected from the entire dorsal flank, 10 to 20 measurements were taken from randomly selected points on the slide. The spectra from each mucus sample were then averaged to take into account the possible heterogenous nature of the mucus. The fish were maintained in holding aquaria for $24 \mathrm{~h}$ allowing for recovery from the procedure before they were released.

Identity and quantity of MAAs in fish mucus. The identity and relative quantity of MAAs in the mucus of cleaner wrasse Labroides dimidiatus $(\mathrm{n}=10)$ and of 5 parrotfish species - Chlorurus sordidus $(\mathrm{n}=6)$, Scarus flavipectoralis $(\mathrm{n}=3)$, S. niger $(\mathrm{n}=3)$, S. schlegelii $(\mathrm{n}=$ 7 ), and S. rivulatus ( $\mathrm{n}=4$ ) - was determined using reverse-phase HPLC (High Performance Liquid Chromatography) (see section 'HPLC mucus analysis' for details). Mucus that was collected in April on Lizard Island was immediately placed in liquid nitrogen. Mucus collected in July at Lizard Island was initially stored at $-4^{\circ} \mathrm{C}$ for $20 \mathrm{~d}$ due to the unavailability of liquid nitrogen, before being transferred to a $-80^{\circ} \mathrm{C}$ freezer. To determine whether variation in initial storage temperature affected the analyses, comparisons of the laboratory UV absorbance of the extracted mucus and MAA quantity and identity were made between parrotfish mucus sampled in these 2 field trips. No differences were found between the mucus samples from the 2 field trips (ANOVA $p>0.5$ ) so the data were pooled.

Geographical comparison. The mucus from Thalassoma lunare (Lizard, $\mathrm{n}=36$; Heron, $\mathrm{n}=22$; North Stradbroke, $\mathrm{n}=6$ ) was collected in $2 \mathrm{ml}$ Eppendorf tubes (minimum volume $10 \mu \mathrm{l}$ ) for mucus dry weight quantification and MAA analysis. The samples were stored in $\mathrm{a}-80^{\circ} \mathrm{C}$ freezer or in liquid nitrogen. The MAAs were extracted, the absorbance of the extract was measured using a UV spectrometer (see section 'Laboratory UV absorbance'), and MAAs were identified and quantified as described above and in the section 'HPLC mucus analysis'. The absorption peaks obtained from the extracted mucus were standardized to mg of mucus dry weight.

Integrated absorbance of each compound was calculated by summing the area underneath the absorbance curve between the minima on either side of the peak $\left(\lambda_{\text {max }}\right)$ of a HPLC chromatogram.

MAA analysis. Sample extraction: Samples were extracted in $1.5 \mathrm{ml}$ of $100 \%$ methanol and homogenized prior to being divided into equal aliquots $(500 \mu \mathrm{l})$ in 3 Eppendorf microcentrifugation tubes. Two aliquots were dried in a centrifugal vacuum evaporator (Christ RVC 2-18) and the remainder was used for mucus dry weight quantification. The residues of the 2 aliquots were each resuspended in a single extraction volume of $500 \mu \mathrm{l}$ of $100 \%$ methanol. Each sample was then mixed using a sonicator in an ice bath (Unisonics) for $20 \mathrm{~min}$ and left to leach for $24 \mathrm{~h}$ at room temperature. The extracts were then centrifuged for $5 \mathrm{~min}$ at $18000 \times g$ (Sigma 12124 Rotor), and the supernatants used for laboratory spectral UV analysis and for MAA separation by reverse-phase chromatography.

In order to quantify the mucus, the third mucus aliquot was placed in pre-weighed aluminium boats and dried in a drying oven. It was then weighed using an analytical milligram scale (Sartorius microscale) accurate to $0.001 \mathrm{mg}$.

Laboratory UV absorbance: The absorbance between 280 and $400 \mathrm{~nm}$ of the fish mucus from 7 fish species was determined by UV spectrophotometry of the $500 \mu \mathrm{l}$ mucus extract (Shimadzu UV-2450 UV visible Spectrometer) using a $1 \mathrm{~cm}$ quartz cuvette against 
a $100 \%$ HPLC-grade methanol baseline. All samples were standardized to $1 \mathrm{mg}$ mucus dry weight. Laboratory UV absorbance refers to all weight standardized mucus absorbance measurements to distinguish the analysis described here from the absorbance measurements made in the field using the fibre optic spectrometer (field UV absorbance).

HPLC mucus analysis: The dried mucus samples were resuspended in $500 \mu \mathrm{l}$ of $100 \%$ methanol and passed through a Millex ${ }^{\circledR} 0.22 \mathrm{~mm}$ syringe-driven filter. Filtered samples $(300 \mu \mathrm{l})$ were added to new glass-shell vials with Milli-Q water $(75 \mu \mathrm{l})$, which were inserted into the HPLC. Mucus extracts from the parrotfish species ( $2 \mu \mathrm{l}$ each) Thalassoma lunare (10 $\mu \mathrm{l})$ and Labroides dimidiatus $(10 \mu \mathrm{l})$ were injected into the HPLC system (Shimadzu LC-10AT VP liquid chromatograph), which was connected to a photo diode array detector (Shimadzu SPD-M10A VP) for MAA separation by HPLC. Optimum separation was achieved using a Brownlee RP-8 column and an aqueous mobile phase of $1 \%$ acetic acid and $80 \%$ methanol with a flow rate of $0.8 \mathrm{ml} \mathrm{min}^{-1}$.

MAAs were identified according to wavelength spectral properties and elution times. A detection wavelength of $360 \mathrm{~nm}$ was used for palythene, while $332 \mathrm{~nm}$ was used for asterina-330 and an initially unknown MAA peak. The latter peak was later identified as mycosporine-N-methylamine serine, which had a $\lambda_{\max }=325 \mathrm{~nm}$ (Dunlap \& Shick 1998). The concentrations were calculated based on the integrated peak area (area under the curve defined by the minima on either side of $\lambda_{\max }$ of the chromatogram).

\section{RESULTS}

\section{Field UV absorbance}

The field UV absorbance of the mucus was highly variable within a species, as demonstrated by an example of 5 Labroides dimidiatus individuals (Fig. 1). This variation was not due to possible heterogeneity in (1) the mucus composition of different body regions, as the same body areas were sampled for each fish, or (2) the sampled mucus on the slide, as the standard deviations of the raw mucus absorbance curves of the replicate measurements across randomly selected areas of the sample from the same fish were low (Fig. 1). Instead, the variation was most likely attributable to differential water content, as laboratory UV absorbance determinations that were standardized to the weight of dry mucus did not show the same degree of variability (Figs. 1 \& 2). Hence, laboratory UV absorbances were used in the statistical analyses.

\section{Laboratory UV absorbance}

The shape of the curve for the laboratory UV absorbance of Labroides dimidiatus from Heron Island (Fig. 2a) appeared to visually differ to the curves for the parrotfishes of Lizard Island (Fig. 2b), with the former's absorbance extending further into the shorter wavelengths. The laboratory UV absorbance of parrotfishes and L. dimidiatus, however, when standardized to mucus dry weight, did not differ among species (ANOVA p > 0.5) (Fig. 2a,b).

\section{MAA identity and quantity}

Chromatogram results showed that Labroides dimidiatus (Fig. 3) and all parrotfishes (Fig. 4) had the MAAs asterina-330 $\left(\lambda_{\max }\right.$ at $\left.330 \mathrm{~nm}\right)$ and palythene $\left(\lambda_{\max }=360 \mathrm{~nm}\right)$ in their mucus. Thalassoma lunare also had palythene plus a different MAA, mycosporine-Nmethylamine serine $\left(\lambda_{\max }=327\right)$, in its mucus.

The mean quantity of asterina-330 differed significantly among the parrotfishes from Lizard Island and Labroides dimidiatus from Heron Island (ANOVA $F_{5,26}=4.7, \mathrm{p}=0.003$ ) (Fig. 4). This difference was due to L. dimidiatus and Chlorurus sordidus having significantly more asterina-330 than Scarus schlegelii (Tukey's p $<0.01$ and $\mathrm{p}<0.05$, respectively) (Fig. 4).

Palythene was always present in Labroides dimidiatus $(\mathrm{n}=10)$ and the parrotfish Scarus rivulatus $(\mathrm{n}=4)$, but only occurred in 33 to $86 \%$ of the other parrotfishes (Chlorurus sordidus: $\mathrm{n}=6,67 \%$; S. niger: $\mathrm{n}=3,50 \%$; S. schlegelii: $\mathrm{n}=7,86 \%$; S. flavipectoralis: $\mathrm{n}=3,33 \%$ ). Palythene levels were compared (Fig. 4) using only parrotfish species, where palythene was found in at

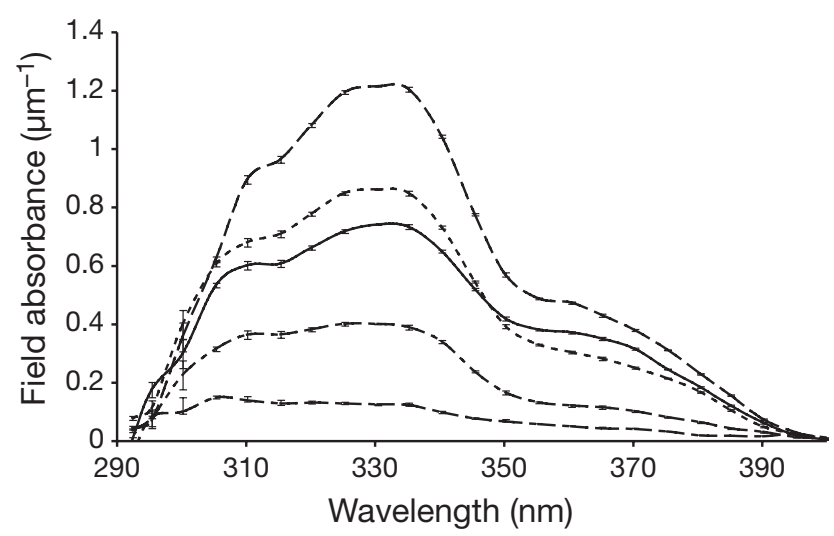

Fig. 1. Labroides dimidiatus. Examples of mean $( \pm \mathrm{SE})$ field UV absorbance for mucus of 5 individuals from Lizard Island. Ten measurements were made of each mucus sample per individual. Absorbance was standardized to mucus thickness 

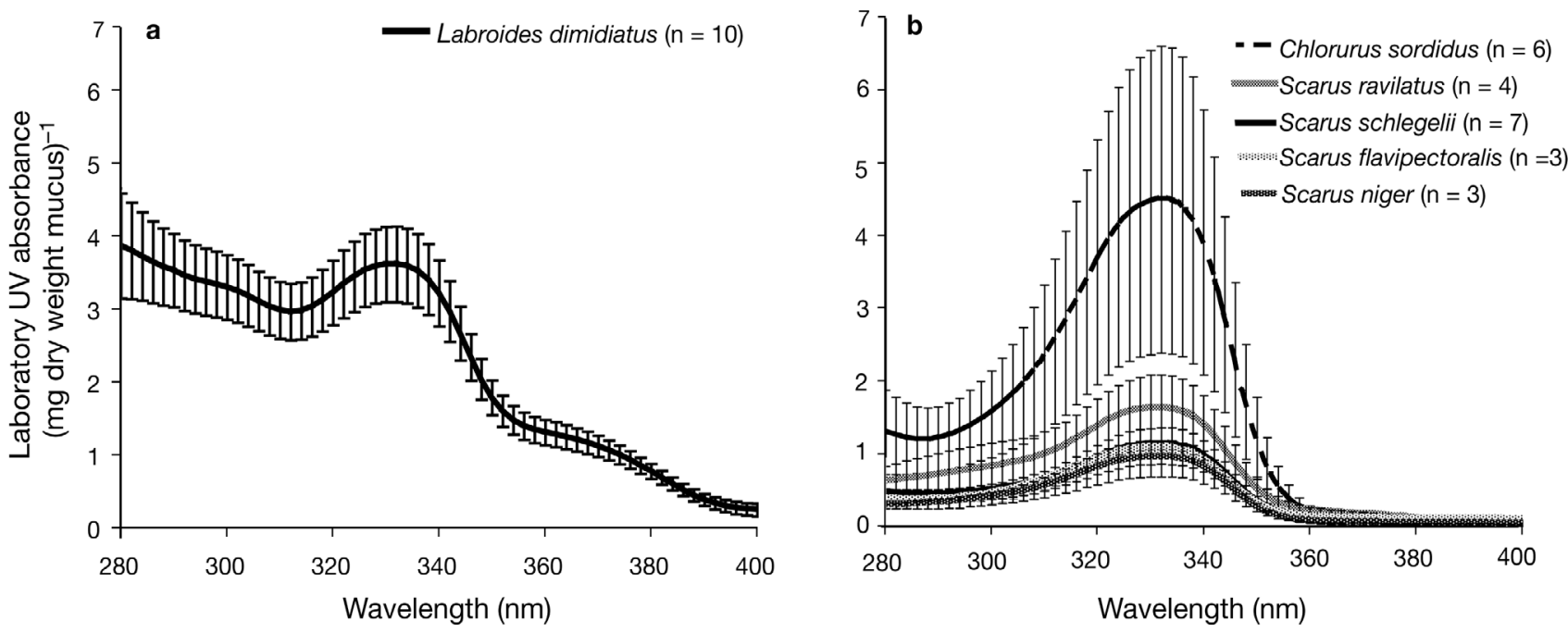

Fig. 2. Labroides dimidiatus, Chlorurus sordidus and Scarus spp. Mean ( \pm SE) laboratory UV absorbance standardized to mg mucus dry weight for (a) L. dimidiatus from Heron Island and (b) parrotfishes from Lizard Island. Species listed in descending order of absorbance

least 2 specimens (C. sordidus, S. schlegelii, and $S$. rivulatus). Palythene absorbance among the parrotfishes and $L$. dimidiatus differed significantly (ANOVA, $F_{5,79}=28.9 ; \mathrm{p}<0.0001$ ) (Fig. 4). This difference was due to $L$. dimidiatus, which had significantly more palythene than any of the parrotfishes (Tukey's p < 0.001 in each case).

\section{Geographical comparison}

The overall shape of the spectra of laboratory UV absorbances for Thalassoma lunare differed slightly among locations (Fig. 5a). HPLC absorbances were $\log _{10}$ transformed to normalize their distribution (D'Agostino/Pearson test of normality). The laboratory

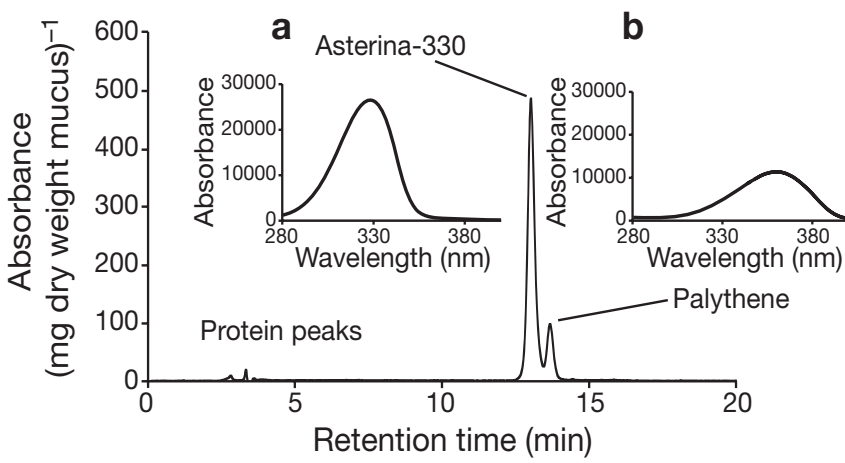

Fig. 3. Labroides dimidiatus. Chromatogram of mucus from L. dimidiatus from Heron Island (using a detection wavelength of $332 \mathrm{~nm}$ ). Inset (a) absorbance spectrum of the mycosporinelike amino acid (MAA) asterina-330. Inset (b) absorbance spectrum of the MAA palythene
UV absorbance of T. lunare mucus, when standardized to dry weight, was significantly lower at North Stradbroke Island than at Lizard Island and Heron Island (ANOVA $F_{2,60}=7.1, \mathrm{p}=0.002$; Tukey's $\mathrm{p}=0.002$ ) (Fig. 5a).

Two MAAs, palythene and mycosporine-N-methylamine serine, were identified in the mucus of Thalassoma lunare. Mucus of fish from North Stradbroke Island had a significantly lower absorbance of mycosporine-N-methylamine serine than did the mucus of fish from Heron Island (ANOVA $F_{2,49}=5.44 ; \mathrm{p}=0.007$, Tukey's $\mathrm{p}=0.007$ ) and Lizard Island (Tukey's $\mathrm{p}=$

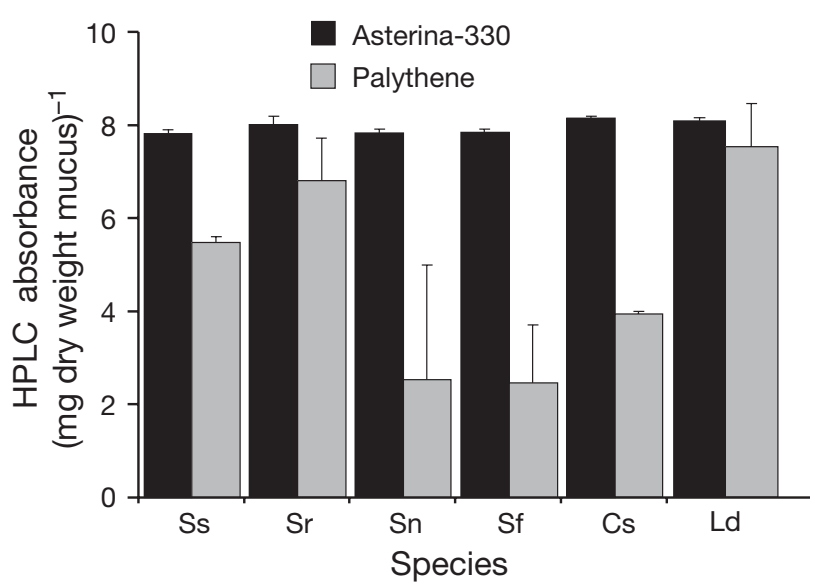

Fig. 4. Labroides dimidiatus, Chlorurus sordidus and Scarus spp. Mean (+SE) HPLC absorbance for mycosporine-like amino acids, asterina-330 and palythene, standardized to mg mucus dry weight, for S. schlegeli (Ss), S. rivulatus ( $\mathrm{Sr}$ ), $S$. niger (Sn), S. flavipectoralis (Sf), and C. sordidus (Cs) and L. dimidiatus $(\mathrm{Ld})$ 

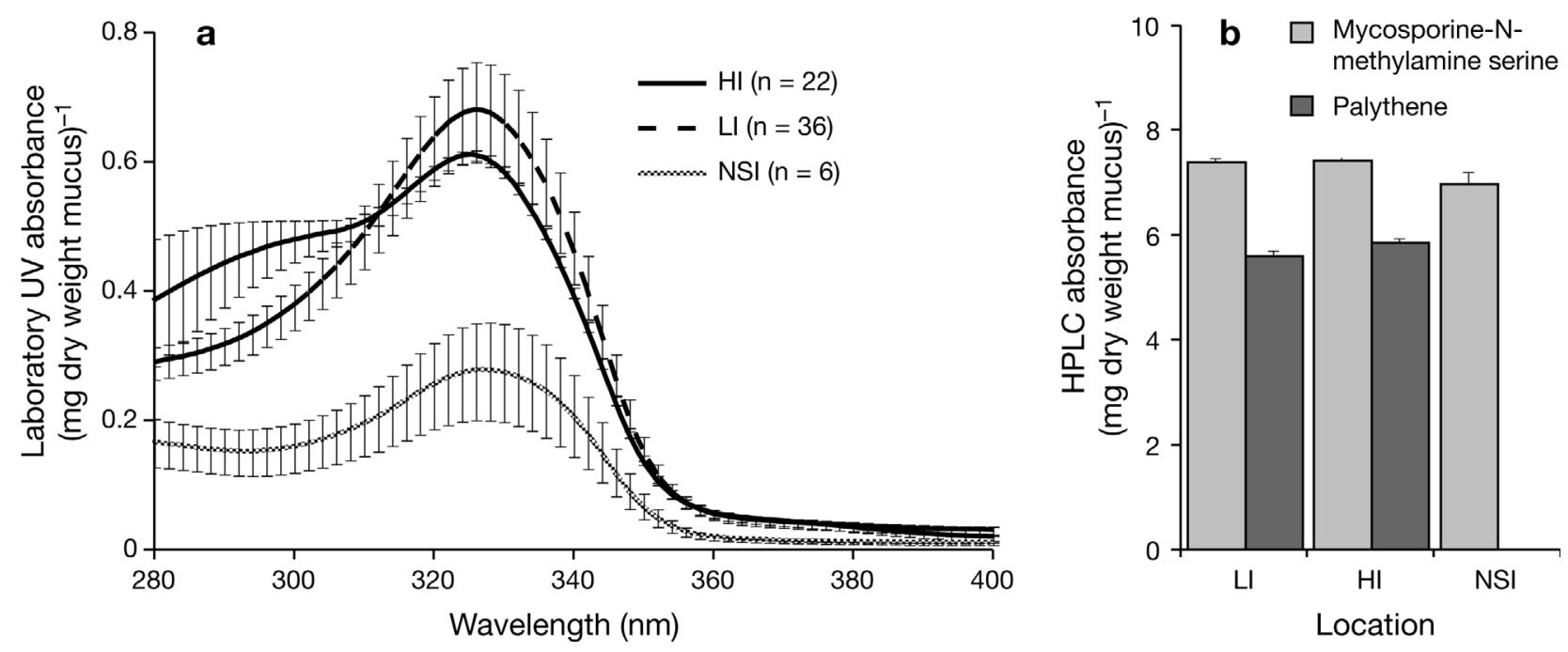

Fig. 5. Thalassoma lunare. (a) Mean $( \pm \mathrm{SE})$ laboratory UV absorbance, standardized to mg mucus dry weight, for T. lunare mucus from Lizard Island (LI), Heron Island (HI), and North Stradbroke Island (NSI). (b) Mean (+SE) HPLC absorbance for mycosporinelike amino acids, mycosporine-N-methylamine serine and palythene, from T. lunare for the same locations as in (a), standardized to mg mucus dry weight

0.011), but no difference was found for mucus between Heron Island and Lizard Island (Tukey's $\mathrm{p}>0.05$ ). The presence of palythene in the mucus of $T$. lunare varied among locations (Heron: $\mathrm{n}=22,82 \%$; Lizard: $\mathrm{n}=36$, $58 \%$ ) (Pearson's $\chi^{2}=18.98, \mathrm{df}=2, \mathrm{p}<0.001$ ). This was largely because palythene was not found in any of the fish from North Stradbroke Island $(n=6)$. Fish from Heron Island had significantly more palythene in their mucus than fish from Lizard Island $\left(t\right.$-test, $t_{27}=-2.095$, $p=0.046$ ) (Fig. 5b).

\section{DISCUSSION}

MAAs were found in the mucus of all fish, irrespective of species and geography. It should be noted, however, that sampling in different locations was also done at different times. Thus, although there were no differences between the 2 sampling times for samples collected at Lizard Island, the possibility that geographical differences are due to temporal variation at the other locations cannot be excluded. Three MAAs, asterina-330, palythene, and mycosporine-N-methylamine serine with absorption peaks at 330,360 and $325 \mathrm{~nm}$, respectively, were identified in the mucus of 7 fish species from Queensland, Australia. These MAAs are common in marine organisms and have been previously found in several invertebrate species from different taxa as well as in the lenses of some fish (Shick \& Dunlap 2002).

The combination of MAAs present and the standardized mucus absorbance varied among species, as well as geographically within a species. Thalassoma lunare consistently had lower laboratory UV absorbance than any of the other species: at Heron Island it was 11 times lower than for Labroides dimidiatus; at Lizard Island it was 1.3 times lower than for the parrotfish Scarus niger, which had the lowest absorbance. Among locations, the mucus of T. lunare from North Stradbroke Island had less laboratory UV absorbance compared with that of $T$. lunare collected from Lizard Island and Heron Island, but there was no difference between the more southern Heron Island and the more northern Lizard Island locations.

All of the fishes analysed in this study are diurnal and live in shallow waters (Randall et al. 1997) and are therefore exposed to UV radiation (Hakkinen et al. 2002). It is therefore perhaps not surprising that all contain MAAs in their mucus. All MAAs found here have their peak absorbance within the UVA range (320 to $400 \mathrm{~nm}$ ) but also extend into the UVB range (280 to $320 \mathrm{~nm}$ ) of the light spectrum. Possession of several different types of MAAs with different absorption maxima provides organisms with a means of UV absorption over a broad range (Tartarotti et al. 2004); thus, these fishes appear to have an effective strategy for UV protection.

Although fishes had different combinations of MAAs, their functional role may be the same. For example, Thalassoma lunare mucus lacked asterina330, which was found in the other species sampled, and instead had mycosporine-N-methylamine serine. Both of these MAAs, however, have overlapping UV absorption spectra and therefore protect the fish within a similar wavelength range (Zamzow 2007). Thus, the UV-protective function of some MAAs may simply be 
replaced by other MAAs. It is possible, however, that different MAAs may also have other important functions, such as osmotic regulation (Shick \& Dunlap 2002) and that their roles may be slightly different. More studies are needed to investigate this possibility.

High variations in MAA absorbance have also been found among algae-invertebrate symbionts (Shick \& Dunlap 2002) and in the lenses of fish (Dunlap et al. 1989). Two factors, diet and UV exposure, are likely to contribute to the variability of UV absorbance in reef fish mucus described here. Fish obtain MAAs from their diet (Mason et al. 1998, Zamzow 2004), with fieldevaluated mucus MAA concentrations rapidly depleting when fed an MAA-poor diet (Zamzow 2004). Algae and plants synthesize MAAs for their own protection (Shick \& Dunlap 2002). Although cleaner fish Labroides dimidiatus mainly eat parasitic gnathiid isopods, they also eat client fish mucus (Grutter 1997), which we show here contains MAAs. Thus, client mucus might be a potential source of MAAs in L. dimidiatus. Indeed, when given a choice between the mucus of the parrotfish Chlorurus sordidus and gnathiid isopods, cleaner fish preferred the parrotfish mucus (Grutter \& Bshary 2004). Although speculative, the presence of high asterina-330 levels in both C. sordidus and $L$. dimidiatus mucus found here may explain this preference and suggest a potential source of MAAs in cleaner fish. Some parrotfish are known to eat algae and hard coral (Bruggemann 1994), which can contain MAAs (Sinha et al. 2001), while others mainly eat detritus from the sand surface (Crossman et al. 2005). The diet of Thalassoma lunare is mainly composed of benthic invertebrates and small fishes (Grant 2004), a food source with unknown MAA levels. The MAAs located in fish mucus may therefore be acquired, either directly from an autotroph, or indirectly from another vertebrate or invertebrate. Given the complexity of these food chains and the potential for differential processing, it is surprising that so many different species of fish share the same 2 MAAs (asterina-330 and palythene). In this context, it would be interesting in future analyses to determine why T. lunare mucus is compositionally so distinct from the rest of the species.

In several algal species, variations in the level of MAAs correspond to variations in UV exposure, i.e. environmental UV photon flux density (Peinado et al. 2004). Furthermore, increased UV radiation leads to increased UV absorbance of fish mucus if the fish are experimentally provided with an artificial MAA-rich diet (Zamzow 2004). This suggests that fish have some capability for regulating their MAA levels in response to differential UV environments. Whether this occurs in the wild, and if so to what extent fish have the ability to vary MAA levels in their mucus and which cues they might use to do this, needs to be determined. For example, it is possible that-instead of the fish responding directly to fluctuations of UV in their environment and modifying MAA levels in their mucus low UV dose rates (e.g. due to latitude, turbidity or depth) reaching their MAA source (e.g. algae or other prey) may result in low MAA levels in their diet and subsequently in their mucus.

Exposure to UV radiation is dependent on geography (Jokiel 1980), the optical quality of the water (Jerlov 1968), the habitat depth (Shick et al. 1996) in the ocean, and the behaviour of the fish. Although we did not specifically test these effects, we can speculate on how they may play a role.

A possible explanation for the observed differences in MAA concentration is the variation in latitude among the islands (Zamzow 2003). UV radiation reaching the earth's surface increases towards the equator (Jokiel 1980) due to the decreased path length (Ilyas \& Barton 1983) and a smaller solar zenith angle from the sun (Shick et al. 1996). Thus, the surface waters of the more northern Lizard Island and Heron Island should receive more UV radiation than the more southern North Stradbroke Island. However, latitude does not explain the lack of difference in UV absorbance between Lizard Island and Heron Island, which are $998 \mathrm{~km}$ apart and located at the northern and southern ends of the GBR, respectively.

Alternatively, differences in the optical quality of the water may explain some of the variation observed here (Zamzow 2007). UV radiation varies with turbidity (Jerlov 1968). The optical characteristic of the oceanic waters along the east coast of Australia are considered to be Jerlov type IB meaning that in the wavelength band of 310 to $400 \mathrm{~nm}, 80$ to $95.5 \%$ irradiance is transmitted per meter of depth (Jerlov 1968). Thus, in oceanic waters at $10 \mathrm{~m}$ depth, the maximum depth at which the fish for this study were collected, fish would be exposed to $16.9 \%$ of the total irradiance from the sun (Jerlov 1968). With increasing distance from the main coast, reef systems experience less sedimentation through runoff and are therefore known to have a higher water clarity (Larcombe et al. 2001). This increased optical clarity allows more shortwavelength radiation to reach deeper ocean depths (Jerlov 1968). Heron Island is $97 \mathrm{~km}$ from the coast while Lizard Island is $27 \mathrm{~km}$ from the coast. Thus, one possible explanation for the lack of difference between Lizard and Heron Island is that higher UV radiation levels reaching the northern, more coastal, Lizard Island are counter-balanced by higher turbidity levels. Studies using a larger sample from different latitudes and manipulating water optical qualities are needed to test these hypotheses. Another potential explanation is that this pattern may be due to 
variation in cloud cover between these locations, as the cloud cover over the southern GBR has been less than that observed for the northern GBR for the last 10 yr (Masiri et al. in press).

UV levels also vary with depth (Shick et al. 1996). It is well known that the habitat and depth range of parrotfishes also varies among species (Randall et al. 1997). For example, Scarus flavipectoralis often inhabits deeper waters and was found to have less UV protection than species, such as Chlorurus sordidus, which are mostly found in shallow habitats. While the fishes in this study were all captured from 5 to $10 \mathrm{~m}$ depths, variation in their microhabitat may explain some of the differences found in mucus UV absorbance. In comparison to most of the other species, the cleaner fish Labroides dimidiatus had a relatively high concentration of all MAAs. L. dimidiatus spends most of its time in open water (Fulton et al. 2001) cleaning other fishes (Grutter 1995) and thus may require more UV protection. More species need to be tested to determine whether the absorbance of L. dimidiatus mucus is indeed unique.

MAA absorbance is probably important for UV protection in coral reef fishes. With UV levels increasing in some areas (Madronich et al. 1998) it is important that we understand the mechanisms of UV protection. Further studies are also needed to explain the occurrence and source of different types and levels of MAAs in fish. Finally, it is important to determine how increased UV radiation levels in the future may affect the ecology of reef fishes.

Acknowledgements. We thank J. Zamzow for help with the review of this manuscript, the staff at the Lizard Island and Heron Island Research Station for their support while in the field, K. Cheney for her statistical advice and help with fish collection, and L. Curtis, C. Jones and B. Cameron for their help with boating, fish collection and aquaria maintenance.

\section{LITERATURE CITED}

Berghahn R, Bullock AM, Karakiri M (1993) Effects of solarradiation on the population-dynamics of juvenile flatfish in the shallows of the Wadden Sea. J Fish Biol 42: 329-345

Bruggemann JH (1994) Parrotfish grazing on coral reefs, a trophic novelty. $\mathrm{PhD}$ thesis, University of Groningen

Carell T, Epple R (1998) Repair of UV light induced DNA lesions: a comparative study with model compounds. Eur J Org Chem 1245-1258

Crossman DJ, Choat JH, Clements KD (2005) Nutritional ecology of nominally herbivorous fishes on coral reefs. Mar Ecol Prog Ser 296:129-142

Dunlap WC, Shick JM (1998) Ultraviolet radiation-absorbing mycosporine-like amino acids in coral reef organisms: a biochemical and environmental perspective. J Phycol 34: 418-430
Dunlap WC, Williams DM, Chalker BE, Banaszak AT (1989) Biochemical photoadaptation in vision: UV-absorbing pigments in fish eye tissues. Comp Biochem Physiol B Biochem Mol Biol 93:601-607

Dunlap WC, Shick MJ, Yamamoto Y (2000) UV protection in marine organisms. I. Sunscreens, oxidative stress and antioxidants. In: Yoshikawa T, Toyokuni S, Yamamoto Y, Naito $\mathrm{Y}$ (eds) Free radicals in chemistry, biology and medicine. OICA International, London, p 200-214

Fleischmann EM (1989) The measurement and penetration of ultraviolet-radiation into tropical marine water. Limnol Oceanogr 34:1623-1629

Fulton C, Bellwood D, Wainwright P (2001) The relationship between swimming ability and habitat use in wrasses (Labridae). Mar Biol 139:25-33

Grant E (2004) Grant's guide to fishes. E. M. Grant Pty Ltd, Scarborough

Grutter AS (1995) Relationship between cleaning rates and ectoparasite loads in coral reef fishes. Mar Ecol Prog Ser 118:51-58

Grutter AS (1997) Spatiotemporal variation and feeding selectivity in the diet of the cleaner fish Labroides dimidiatus. Copeia 346-355

Grutter AS, Bshary R (2004) Cleaner fish, Labroides dimidiatus, diet preferences for different types of mucus and parasitic gnathiid isopods. Anim Behav 68:583-588

Hakkinen J, Vehniainen E, Ylonen O, Heikkila J and others (2002) The effects of increasing UVB radiation on pigmentation, growth and survival of coregonid embryos and larvae. Environ Biol Fishes 64:451-459

Ilyas M, Barton IJ (1983) Surface dosage of erythemal solar ultraviolet radiation near the Equator. Atmos Environ 17: 2069-2073

Jerlov NG (1968) Optical oceanography, Elsevier, Amsterdam

Jokiel PL (1980) Solar ultraviolet radiation and coral reef epifauna. Science 207:1069-1071

Karentz D (2001) Chemical defenses of marine organisms against solar radiation exposure: UV-absorbing mycosporinelike amino acids and scytonemin. In: McClintock JB, Baker BJ (eds) Marine chemical ecology. CRC Press, Boca Raton, FL, p 481-520

Karsten U, GarciaPichel F (1996) Carotenoids and mycosporine-like amino acid compounds in members of the genus Microcoleus (Cyanobacteria): a chemosystematic study. Syst Appl Microbiol 19:285-294

Larcombe P, Costen A, Woolfe KJ (2001) The hydrodynamic and sedimentary setting of nearshore coral reefs, central Great Barrier Reef shelf, Australia: Paluma Shoals, a case study. Sedimentology 48:811-835

Madronich S, McKenzie RL, Bjorn LO, Caldwell MM (1998) Changes in biologically active ultraviolet radiation reaching the earth's surface. Photochem Photobiol 46:5-19

Masiri I, Nunez M, Weller E (in press) A ten-year climatology of solar radiation for the Great Barrier Reef: implications for recent mass coral bleaching events. Int J Remote Sensing

Mason DS, Schafer F, Shick JM, Dunlap WC (1998) Ultraviolet radiation-absorbing mycosporine-like amino acids (MAAs) are acquired from their diet by medaka fish (Oryzias latipes) but not by SKH-1 hairless mice. Comp Biochem Physiol Part A Mol Integr Physiol 120:587-598

Peinado NK, Diaz RTA, Figueroa FL, Helbling EW (2004) Ammonium and UV radiation stimulate the accumulation of mycosporine-like amino acids in Porphyra columbina (Rhodophyta) from Patagonia, Argentina. J Phycol 40: 248-259

Randall JE, Allen GR, Steene R (1997) Fishes of the Great 
Barrier Reef and Coral Sea. University of Hawaii Press, Honolulu, HI

Reakla-Kudla ML (1997) The global biodiversity of coral reefs: a comparison with rain forests. In: Reakla-Kudla ML, Wilson DE, Wilson EO (eds) Biodiversity II: understanding and protecting our natural resources. Joseph Henry, Washington, DC

Sharma JG, Masuda R, Tanaka M (2005) Ultrastructural study of skin and eye of UVB irradiated ayu Plecoglossus altivelis. J Fish Biol 67:1646-1652

Shick JM, Dunlap WC (2002) Mycosporine-like amino acids and related gadusols: biosynthesis, accumulation, and UV-protective functions in aquatic organisms. Annu Rev Physiol 64:223-262

Shick JM, Lesser MP, Jokiel PL (1996) Effects of ultraviolet radiation on corals and other coral reef organisms. Global Change Biol 2:527-545

Sinha RP, Klisch M, Groniger A, Hader DP (2001) Responses of aquatic algae and cyanobacteria to solar UV-B. Plant Ecol 154:219-236

Tartarotti B, Baffico G, Temporetti P, Zagarese HE (2004)

Editorial responsibility: John Choat (Contributing Editor), Townsville, Queensland, Australia
Mycosporine-like amino acids in planktonic organisms living under different UV exposure conditions in Patagonian lakes. J Plankton Res 26:753-762

WMO (World Meteorological Organization), UNEP (United Nations Environment Programme) (2006) Scientific assessment of ozone depletion: 2006. Scientific Assessment Panel of the Montreal Protocol on Substances that Deplete the Ozone Layer, Montreal

Zamzow JP (2003) Ultraviolet-absorbing compounds in the mucus of temperate Pacific tidepool sculpins: variation over local and geographic scales. Mar Ecol Prog Ser 263: $169-175$

Zamzow JP (2004) Effects of diet, ultraviolet exposure, and gender on the ultraviolet absorbance of fish mucus and ocular structures. Mar Biol 144:1057-1064

Zamzow JP (2007) Ultraviolet-absorbing compounds in the mucus of shallow-dwelling tropical reef fishes correlate with environmental water clarity. Mar Ecol Prog Ser 343: 263-271

Zamzow JP, Losey GS (2002) Ultraviolet radiation absorbance by coral reef fish mucus: photo-protection and visual communication. Environ Biol Fishes 63:41-47

Submitted: February 13, 2007; Accepted: August 14, 2007 Proofs received from author(s): December 16, 2007 